\title{
STARODRUKI W KSIĘGOZBIORZE PARAFII RZYMSKOKATOLICKIEJ W KUMOWIE
}

\section{Streszczenie}

Parafia rzymskokatolicka powstała w Kumowie w 1434 r. Jak wszystkie parafie posiadała swój księgozbiór, na który zawsze składały się księgi liturgiczne. Wiele parafii posiadało też $\mathrm{w}$ swoich zbiorach książki pomocne w duszpasterstwie, np. zbiory kazań. W okresie reformy trydenckiej tych książek przybywało, szczególnie dzięki pracy zakonu jezuitów, którego członkowie trudnili się pisarstwem teologicznym i działalnością wydawniczą. W XVII i XVIII wieku przybywało też książek w zbiorach parafialnych. Te procesy nie ominęły również parafii w Kumowie. Nie znamy dokładnie księgozbioru parafialnego z okresu staropolskiego z powodu niezachowania się jego inwentarza. Informacji dostarczają jedynie protokoły z wizytacji biskupich parafii, jednak trudno jest oddzielić na ich podstawie książki należące do kościoła od prywatnych, będących własnością kolejnych proboszczów. Możemy jedynie wskazać niektóre, powtarzające się w raportach wizytatorów, co do których mamy pewność, że stanowiły własność parafii. Zbiór starodruków powiększył się w drugiej połowie XVIII wieku dzięki spuściznom na rzecz parafii dwóch jej plebanów: ks. Antoniego Borowskiego i ks. Antoniego Wołoszyńskiego. Do dzisiaj zachowało się 25 starodruków, które przez lata niszczały w piwnicy plebanii.

Artykuł niniejszy jest przyczynkiem do badań nad księgozbiorami parafialnymi w archidiecezji lubelskiej - dotąd nieprzebadanymi i nieznanymi. Badania w tym zakresie warto podejmować, bowiem księgozbiory stanowią dobra kultury kryjące często rzadkie egzemplarze, niszczejące bezpowrotnie.

Słowa kluczowe: Kumów; parafia w Kumowie; księgozbiór; starodruki; diecezja lubelska

* Ks. Włodzimierz Bielak - dr hab. historii Kościoła, prof. w Katedrze Historii Kościoła; Instytut Nauk Teologicznych KUL; e-mail: bielakwl@kul.pl

https://orcid.org/0000-0002-3883-5615 


\section{Wstęp}

Parafia pod wezwaniem Nawiedzenia Najświętszej Marii Panny w Kumowie zostałą erygowana przez biskupa chełmskiego, Jana Biskupca, w 1434 roku. Sam Kumów był pod względem kościelnym ośrodkiem ważnym, bowiem znajdowała się tu również letnia rezydencja biskupów chełmskich, z której chętnie korzystali do XIX wieku.

Jak większość parafii w okresie staropolskim posiadała swój księgozbiór nie ograniczający się do obecnych w każdym kościele ksiąg liturgicznych, lecz służący pomącą w prowadzeniu duszpasterstwa. Dzisiaj z tego księgozbioru zachowało się tylko część książek.

Postaramy się przedstawić pewne uwagi na temat rozwoju księgozbioru kumowskiego w okresie staropolskim i jego charakteru, posługując się informacjami zawartymi $\mathrm{w}$ protokołach wizytacyjnych parafii w Kumowie. Zaprezentujemy też zachowane tam do dziś starodruki. Jest to przyczynek do badań nad księgozbiorami parafialnymi w Archidiecezji Lubelskiej. Wiele z nich jest nieprzebadanych i nieznanych, a kryją w sobie nieraz druki rzadkie, które niszczeją, czasem bezpowrotnie.

\section{Gromadzenie księgozbioru}

Zasób księgozbioru parafii w Kumowie w okresie staropolskim jest trudny do odtworzenia z powodu niezachowania się jego inwentarza. Taki inwentarz z pewnością istniał, o czym świadczy nota proweniencyjna umieszczona na jednym ze starodruków informująca o wpisaniu go do katalogu książek parafii kumowskiej' Niestety, nie udało się go odnaleźć. Jedynym źródłem informacji pozostają protokoły z wizytacji parafii. Zapisy wizytatorów dotyczące książek znajdujących się w kościele lub na plebanii mają jednak znaczące wady: 1) w wielu przypadkach nie pozwalają jednoznacznie zidentyfikować poszczególnych dzieł, 2) nie rozstrzygają problemu czyją własność stanowiły książki, czy należały do parafii, czy były mnieniem aktualnego proboszcza, 3) nie ma pewności czy uwzględniano wszystkie księgi, czy tylko wybrane. Pierwsza trudność jest oczywiska. Zapisy typu: „Hosius”, „Biblia stara”, „Constitutiones synodales”, „Doctrina” itp. są zbyt ogólne, by można było z całą pewnością stwierdzić, o które dzieło konkretnie chodzi. Problemy drugi i trzeci wiążą się ze sobą i warto poświęcić im nieco uwagi.

Pierwsze wzmianki o księgozbiorze w parafii Kumów pochodzą z 1672 roku. W wizytacji przeprowadzonej 20 stycznia odnotowano 16 książek kościelnych w tym dwie rękopiśmienne ${ }^{2}$. Nie wspomniano o księgach liturgicznych. Wizytacja z 17 września 1714 roku $^{3}$ wymienia już księgi liturgiczne, których liczbę trudno określić ze względu na ogólną wzmiankę o mszałach, bez podania liczby egzemplarzy. Oprócz mszałów było trzy rytuały, dwa brewiarze i ewangeliarz. Innych książek wymieniono pięć, w tym trzy znane z roku 1672. Najobszerniejszy wykaz książek pochodzi z protokołu wizytacyjnego z 13 września 1726 roku.

\footnotetext{
${ }^{1}$ Aneks, poz. 15.

${ }^{2}$ Archiwum Archidiecezji Lubelskiej (dalej: AAL), sygn. Rep 60, A 150, k. 195 - 198v

${ }^{3}$ AAL, sygn. Rep 60, A 152, k. 159v.
} 
Wymieniono w nim aż 40 książek (bez ksiąg liturgicznych), wśród nich znane już z wcześniejszego okresu (1714). Z kolei wizytatorzy z lat 1763 i 1777 o książkach znanych w roku 1726 już nie wspominają, z wyjątkiem starego ewangeliarza i jednego zbioru kazań.

Powstają więc wątpliwości: czy wizytatorzy w większości wypadków mało interesowali się księgozbiorem parafialnym, dlatego nie opisywali go zbyt szczegółowo, czy też w przypadkach, gdy zaznaczono dość obfity zbiór książek, prywatne księgozbiory proboszczów traktowali jako parafialne i oba umieszczali w jednym indeksie? Ta druga możliwość wydaje się najbardziej prawdopodobna. Do przyjęcia takiej opinii skłania nas analiza akt wizytacyjnych z XVIII wieku. Jak wspomniano wyżej, w 1714 roku parafia miała posiadać jedynie 5 książek (pomijając księgi liturgiczne), czyli od poprzedniej wizytacji (1672), a więc przez 42 lata, przybyło zaledwie dwie, natomiast w ciągu zaledwie dwunastu lat (1726) księgozbiór parafialny powiększyłby się aż do 40 egzemplarzy, by czterdzieści lat później (1763) nie pozostało po nim w zasadzie śladu. Takie zmiany w księgozbiorze są mało prawdopodobne. Owszem, w protokole wizytacyjnym z $1798 \mathrm{roku}^{4}$ znowu mamy informację o kilkudziesięciu książkach, ale nie może to dziwić, bowiem są poświadczone dwie darowizny książek na rzecz parafii: ks. Antoniego Borowskiego ${ }^{5}$ i ks. Antoniego Wołoszyńskiego - tę drugą potwierdzają ekslibrisy zachowanych do dzisiaj starodruków. Znowu nie wiemy, czy nie zamieszczono wśród ksiąg parafialnych własnych książek ówczesnego proboszcza, ks. Ignacego Gorajewskiego ${ }^{6}$. W każdym razie, możemy przyjąć, że własny księgozbiór parafii w okresie staropolskim nie był zbyt obfity, szczególnie do lat siedemdziesiątych XVIII wieku.

Jako najstarsze książki wchodzące do księgozbioru parafii, wynieniane przynajmniej w dwóch kolejnych protokołach wizytacyjnych z lat 1672-1763, możemy wymienić:

1) Kazania na niedziele i święta ks. Adama Fabiana Birkowskiego?

2) Flores exemplorum ${ }^{8}$

3) Arka testamentu ks. Szymona Starowolskiego";

${ }^{4}$ Archiwum parafii w Kumowie, [brak sygnatury], Visitatio generalis ecclesiae et beneficii parochialis kumoviensis per ... Adalbertum Leszczyc de Skarszewski ... Episcopum Hełmensem et Lublinensem coadiutorem Abbatem Suleioviensem ... 1798, k. $17^{\mathrm{r}}$.

${ }^{5}$ AAL, Rep 60, A. 164, k. $69^{\text {r. }}$.

${ }^{6}$ Objął urząd proboszcza 22 kwietnia 1796 roku; był kanonikiem honorowym katedry chełmskiej (Visitatio generalis ecclesiae et beneficii parochialis kumoviensis, k. $5^{\mathrm{r}}-5^{\mathrm{v}}$ ).

${ }^{7}$ Kazania na niedziele i święta doroczne. Przez X. D. Fabiana Birkowskiego zakonu ś. Dominika Kaznodziejskiego, napisane i wydane. Na każda niedzielę po dwojgu kazań, i na swięta przedniejsze ..., W Krakowie, w drukarni Andrzeja Piotrkowczyka typographa K. J. M, 1620; drugie wydanie opublikowano w dwóch oddzielnych tomach w latach 1623 - tom I i 1628 - tom II; E XIII, 143.

${ }^{8}$ Mające kilka wydań: Flores exemplorum sive catechismus historialis ... auctore R. P. Antonio Daureoultio - zob. katalog Biblioteki Narodowej: https://katalogi.bn.org.pl/discovery/search?query=any,contains,Flores $\% 20$ exemplorum $\&$ tab $=$ LibraryCatalog\&sortby=date d $\&$ vid $=48$ OMNIS NLOP:48OMNIS_NLOP\&facet=frbrgroupid,include, $9065282683600106852 \&$ lang $=$ pl\&offset $=0$

${ }^{9}$ Arka Testamentu, Zamykająca w sobie kazania niedzielne całego roku, na dwie czesści rozdzielone, z których Pierwsza Część Pars Hyemalis Jest Rzeczona, a przez ks. Szymona Starowolskiego, kantora tarnowskiego, ku pożytkowi i zbudowaniu duchownemu, nabożnym ktholikom wystawiona. 
Inne, wymienione w tym czasie książki parafialne mogły być własnością ówczesnych proboszczów.

W 1777 roku wizytator podał wiadomość o przekazaniu parafii w Kumowie przez ks. Antoniego Borowskiego następujących druków ${ }^{10}$ :

1) Katechizm Rzymski ${ }^{11}$

2) Theologus moralis ks. F. Januszowskiego ${ }^{12}$

3) Myśl pokutującego człowieka ${ }^{13}$

4) Prawdy wieczne Rosignoli ${ }^{14}$

5) Kaznodzieja Kolumna o cnotach

6) Kaznodzieja Wujek ${ }^{15}$

7) Kaznodzieja Rychłowski ${ }^{16}$

8) Maruli Spalatensis ${ }^{17}$

9) Katechizm. Chleb duchowny ${ }^{18}$;

W Krakowie, w Drukarni Krzysztofa Schedla, I. K. M. Typogr., 1648, Część wtora, Pars Aestivalis rzeczona, teraz świeżo ... W Krakowie, w Drukarni Krzysztofa Schedla, I. K. M. Typogr., 1649; E XXIX, 187-188.

${ }^{10}$ AAL, Rep 60, A 164, k. 209'.

${ }^{11}$ Niemożliwe do zidentyfikowania.

12 Zob. Aneks, poz. 9.

${ }^{13}$ Zapewne chodzi o Myśli pokutujacego człowieka, przy Zranionych Nogach Jezusowych grzechy swoje opłakujacego, w refleksyjach na siedm Psalmów pokutnych wyrażone, dla pożytku dusz niewinna krwią Zbawiciela Okupionych. Do druku podane przez Księdza Augustyna Wessla, Biskupa Inflantskiego, Piltynskiego, Opata Jędrzejowskiego roku od wydania na okupienie świata Boga i Człowieka 1724, w Krakowie, w Drukarni Wdowy i Dziedziców Franciszka Cezarego, J. K. M. i J. O. X. Biskupa Krak. Xcia Siewierskiego, Ordyn. Typografá, 1724 (albo w Poznaniu w Druk. Akad., 1754); E XXXII, 396-397.

${ }^{14}$ Prawdy wieczne wyrażone $w$ naukach potrzebnych tym osobliwie, co ćwiczenia duchowne, albo rekollekcyje czynia, zebrane od Ojca Karola Grzegorza Rossignoli Societatis Jesu a z włoskiego na polski język przettumaczone - wiele wydań, zob. E XXVI, 367-368.

${ }^{15}$ Nie wiadomo o jaki zbiór kazań chodzi, zob. E XXXIII, 383 nn.

${ }^{16}$ Kazania na niedziele całego roku przez ks. Franciszka Rychłowskiego zak. S. Franciszka Reformata ... w Matej Polszcze Prowicyjatas. Theol. Professora napisane i wydane. Na każda niedziele po dwojgu kazań, w Krakowie w Druk. Stanisława Piotrkowczyka 1664 albo Kazanie dwojakie na niedziele całego roku. Teraz świeżo ... napisane i wydane przez ks. Franciszka Rychłowskiego zakonu Franciszka świętego, Reformata. Na ten czas w Małej Polszcze prowincyjała, a przedtym kaznodzieje i Świętej Theologiej professora, w Krakowie w Drukarni Dziedziców Krzysztofa Szedla 1672 (to samo: w Krakowie w Drukarni Mikołaja Aleksandra Szedla, 1695) E XXVI, 513-514 - że chodzi o kazania na niedziele, zaświadcza protokół wizytacyjny z 1798 roku (Visitatio generalis ecclesiae et beneficii parochialis kumoviensis, k. 17 ).

${ }^{17}$ Wizytacja z roku 1798 podaje: Opera Maruli Spalatensis (Visitatio generalis ecclesiae et beneficii parochialis kumoviensis, k. 17r). Może więc chodzić o Opera Omnia M. Maruli Spalatensis, Nunqvam Antea Simul Excusa, divisa in duas Partes: quarum prior dictorum factorumque memorabilium Libros sex continet; Siue, De bene beateq[ue] vivendi institutione, ad normam vita Sanctorum utriusque Testamenti collectos atque in ordinem digestos. Posterior vero, De fide, spe et charitate libros septem, Opus longe vtilissimum et parabolas quinquaginta. Antverpiae, ex Officina Martini Nutij, 1601 (zob. katalog Biblioteki Narodowej: https://katalogi.bn.org.pl/discovery/fulldisplay?docid=alma9910825592805606\&context=L\&vid=48OMNIS_NLOP:48OMNIS_NLOP\&lang=pl\&search_scope=NLOP_IZ_NZ\&adaptor=Local\%20Search\%20Engine\&tab $=$ LibraryCatalog\&query=any,contains,Maruli\&offset=0).

18 Jedno z wydań: Chleb Duchowny, wszytkim chrześcianom na posiłek $w$ drodze do nieba idacym wystawiony. Albo raczej, Katechizm na świat polski wychodzacy. Krótkie nauki Chrześciań- 
10) Liber benedictionum Gelasy de Cilia ${ }^{19}$

11) Sententie Andreae Eborensis Lusitani ${ }^{20}$.

Z zachowanych dzisiaj w parafii w Kumowie starodruków dwa mają bezpośrednio poświadczoną ekslibrisami proweniencję od ks. Antoniego Borowskiego (Aneks, poz. 9, 15). Cztery został opisane jako należące do kościoła kumowskiego (Aneks, poz. 2, 16, 21), w tym jeden znajduje się w spisie ksiąg po zmarłym w 1773 roku $^{21}$ ks. Borowskim (Aneks, poz. 12).

Drugim darczyńcą był kolejny proboszcz w Kumowie, ks. Józef Wołoszyński (zm. 1796 $)^{22}$. Jego proweniencję nosi 8 przechowywanych w Kumowie starodruków (Aneks, poz. 3, 7, 8, 10, 18, 20, 23, 24). Na niektórych swoich książkach zapisał cenę za jaką je kupił.

Źródło pozyskania przez parafię kumowską pozostałych starodruków będących dziś w jej posiadaniu jest trudny do ustalenia. Jeden pochodził z biblioteki Kolegium Pijarów w Chełmie (Aneks, poz. 17) i nie wiadomo jak trafił do Kumowa. Dwa były własnością osób prywatnych: brata Kajetana Kisielowskiego (vel Kisielewskiego) w 1789 roku, a później Jana Dymowskiego w 1820 roku (Aneks, poz. 4), Andrzeja Ligięzy (?) (Aneks, poz. 5). Pozostałe nie noszą not proweniencyjnych.

\section{Charakter księgozbioru}

Księgozbiór parafii w Kumowie był związany z duszpasterstwem. Przeważały w nim zbiory kazań, w tym popularnych w wielu osiemnastowiecznych parafiach autorów: Adama Fabiana Birkowskiego OP, ks. Szymona Starowolskiego, Pawła Kaczyńskiego SJ. O poczytności tych autorów świadczy stopień zużycia ksiąg. Wizytator parafii kumowskiej zapisał w 1726 roku, że książki zawierające kazania Birkowskiego i Starowolskiego były w złym stanie i podarte. To zaczytanie nastąpiło zapewne w ciągu zaledwie 12 lat, bowiem jeszcze w 1714 roku zostały określone jako ,integri”23. Korzystano zapewnie z nich bardzo intensywnie. Z kolei na kartach kazań Pawła Kaczyńskiego zachowały się odręczne glosy marginalne pochodzące zapewne od czytelników. Duszpasterze kumowscy korzystali zarówno z autorów polskich, do których należy zaliczyć, oprócz już wspomnianych, słynnych kaznodziejów Jakuba Wujka SJ, Piotra Skargi, czy też krakowskiego

skiej, w sobie zebranie mający. Nad to: Jako najłatwiejszym i osobliwszym do pojęcia każdemu, tudzież katechizowania sposobem. Przez Jana Stanisława Kostkę Wuykowskiego, Kanonika Pułtuskiego, napisany ... Z przydatkiem na końcu Przewodniká na drogę wiecznośći dla dusz ludzkich obmyślonego, Kapłanom zaś, a osobliwie pasterzom na śmierć dysponujacym, ku używaniu podanego ... E XXXIII, 401-402.

${ }^{19}$ Zob. Aneks, poz. 12.

${ }^{20}$ Prawdopodobnie chodzi o jedno z wydań: Sententiae et exempla ex probatissimis quibusque scriptoribus collecta et pro loco communes digesta per Andream Eborensem Lusitanum et ne oneroso volumine gravaretur lector totum opus in duos divisum est tomos quorum alter sentencias alter exempla refert ... - wydania 1583 i 1621 roku posiada Biblioteka Jagiellońska.

${ }^{21}$ Datę jego śmierci potwierdza wizytacja z roku 1777 (AAL, Rep 60, A 164).

${ }^{22}$ J. R. Marczewski, Dzieje chetmskiej kapituly katedralnej obrządku łacińskiego, Lublin 2013, s. 783,808 .

${ }^{23}$ AAL, Rep 60, A 152, k. 549v. 
Jezuity Kaspra Balsama, jak i zagranicznych, np. Wincenta Houdry SJ. Do tej grupy książek należały pomoce do kazań, np. nauki biskupa chełmskiego Antoniego Okęckiego wydane przez pijara Samuela Wysockiego.

Mniej licznie, zwykle w pojedynczych egzemplarzach, były reprezentowane dzieła z zakresu teologii dogmatycznej i moralnej, ascetyki, prawa kościelnego, pisma Ojców Kościoła. Nie mogło oczywiście zabraknąć Biblii oraz książek liturgicznych.

\section{Przechowywanie księgozbioru}

Nie jesteśmy w stanie opisać warunków przechowywania książek w parafii w Kumowie w okresie staropolskim, jak to bywa w z wieloma księgozbiorami parafialnymi ${ }^{24}$. Przez ostatnie lata starodruki kumowskie znajdowały się $\mathrm{w}$ piwnicy, gdzie niszczały w zapomnieniu. $\mathrm{W}$ ostatnim czasie poddano je osuszaniu i odgrzybianiu. Wiele z nich wymagałoby gruntownej konserwacji.

\section{ANEKS \\ STARODRUKI OBECNIE ZACHOWANE W PARAFII W KUMOWIE}

1. ADM. R. P. F. Luciiferraris Soler-Alexandrini Ordinis Minor Regular Observ. S. P. Francisci, lectoris jubilati, exprovinc. examinator. synodalis ac S. Officii consultoris prompta bibliotheca canonica, juridica, moralis, theologica, nec non ascetica, polemica, rubricistica, historica de principaliorubus et fere omnibus quae in dies occurrunt nec penes omnes facile ac prompte reperiri possunt ex utroque jure, summorum Pontificum constitutionibus ac praesertim supremi Magistrii Benedicti XIV. ex conciliis, Sacrarum Congregationum decretis, Sacre Romae Rotae decisionibus ac probatissimis et selectissimis auctoribus accurate collecta, adaucta, in unum redacta et ordine alphabetico congesta, ac in octo tomos distributa. Post plures italicas editio postrema absolutissima. Innumeris fere locis ad auctorum fidem magno labore restituta R. P. Philippi a Carboneano Ord. Min. de Observantia lectoris jubilati notis criticis, nec non supplementis et additionibus luculentissimis a Clariss. Anonymo Jurisconsulto Romano hactenus in lucem editis, suosque loco nunc primum appositis, ita illustrata et auctior reddita ut caeteris omnibus longe antecellat. Adduntur auctoris vindiciae. In easdem notas et addiciones, una cum indice generali accuratissimo. Tomus septimus STVXZ. Romae, curis et sumptibus Societatis Venetae, $1766,4^{\circ}$. o. E.

2. Annus Apostolicus continens conciones praedicabiles stilo perspicuo elaboratas claraque methodo concinnatas. Auctore R. P. Fr. Zacharia Laselve Sacrae Theologiae lectore necnon Provinciae Recollectorum Sanctissimi Sacramenti seu Tolosanae alumno. Tomus primus complectens conciones I. Pro toto Adventu. II. Pro tempore

${ }^{24}$ Uwagi na ten temat: T. Moskal, Biblioteki parafialne $w$ archidiakonacie sandomierskim w XVIII wieku, Sandomierz 2005, s. 84-86. 
Quadragesimae. III. Pro omnibus et singulis totius anni diebus dominicis. Editio novissima caeteris auctior et emendatior. Venetiis, ex Typographia Remondiniana, 1759, $8^{\circ}$, o. E.

3. Benedicti XIV Pont. Opt. Max. olim Prosperi Card. de Lambertinis primum Anconitate Ecclesiae Episcopi deinde Bononiensis Archiepiscopi, De Sacrosancto Missae Sacrificio libri tres. Editio quarta latina post plurimas italas auctior et castigatior ad usum Academiae Liturgicae Conimbricensis. Accedunt Apendices ex operibus SS. Domini Nostri petitae, una cum indice multiplici ad majorem Auditorum profectum qui Novae Sacrorum Rituum Scholae in Collegio Romano Societatis Jesu intererunt. Patavii Typis Seminarii apud Joannem Manfre, 1764, $4^{\circ}$, o. E.

4. Biblia sacra vulgatae editionis Sixti Quinti Pont. Max. Ivssv recognita atque edita, Antverpiae ex Officina Plantiniana apud Balthasarem Moretum et Viduam Joannis Moreti Io. Meursium 1628, $8^{\circ}$. o. E

5. Biblia sacra vulgatae editionis Sixti V Pont. Max. Ivssv recognita et Clementis VIII auctoritate edita, Colloniae Agrippinae sumptis Francisci Iacobi Mertzenich 1609, $8^{\circ}$. o. E

6. Cornu copiae concionum sacrarum et moralium formatarum pars secunda sive Tractatus Marialis de laudibus et praerogativis Beate Mariae Virginis divisus in viginti quatuor conciones, quibus adjunguntur duo sermones panegyrici, unus de dilecto illius Filio Joanne, alter de amato ejus Sponso Josepho. Authore R.P.F. Carolo van Horn Gandensi S. T. Doctore, Ord. F. Erem. S. P. Augustini. Cum duplici indice copioso rerum memorabilium et materiarum facile applicabilium cunctis totius anni deiparae festis. Coloniae Agrippinae, apud Hermannum Demen sub signo Monocerotis, 1688, $4^{\circ}$, o. E.

7. Cornucopiae concionum sacrarum et moralium formatarum. Auctore R.P.F. Carolo van Horn, S.T.D. Ord. Eremit. S. P. Augustini Conventus Gandav. Religiosi. Pars prima. Supra cunctas ferias et dominicas totius quadragesimae nec non luctuosam Christi Domini Passionem cum triplici indice. I. Concionum et evangeliorum quae tractantur. II. Concionatorio in omnes anni dominicas quibus contenti discursus sine addito ad longum applicantur. III. Rerum memorabilium et curiositatum quae memorantur. Opus elaboratum. Variis conceptibus praedicabilibus, dilucidis sacrae scripturae locorum explicationibus, sacra ac profana historia, SS. PP. authoritatibus mire refertum, facili methodo concinnatum. Atque adeo omnibus parochis ac concionatoribus, praesertim pluribus impeditis apprime utile ac nesessarium. Adjungitur quoque ad faciliorem methodum concionandi totius libri synopsis in qua adjuncta repetier lector objecta et materias de quibus quaelibet concio praecise tractat et quibus dominicis et festis totius anni, facili negotio appropriari possit. Coloniae Agrippinae, apud Hermanum Demen, $1688,4^{\circ}$, o. E.

8. Hortus Pastorum, Sacrae doctrinae floribus polymitus, Authore R.D. Jac. Marchantio oppidi conviniensis pastore et decano, S. Theologiae quondam professore. Una cum candelabro mystico aliisque opusculis ejusdem Authoris. Nunc recens a mendis expurgatus novoque ordine dispositus et in faciliorem methodum redactus. Studio et opera Michaelis Alix, Parochi Ecclesiae Sancti Audoeni de Eleemosyna Diocesis Parisiensis. Opus singulis animarum curam habentibus concionatoribus seu missio- 
nariis perutile ac necessarium. Editio ultima et plane recognita. Materia et numerus singulorum librorum in pagina, ab hac, sexta indicantur. Accessit tabula nova rerum, verborum et concionum in Evangelia, nunquam antehac edita. Lugduni, sumptibus Societatis, $1752,6^{\circ}$. o. E

9. In nomine Sanctissimae Trinitatis. Sententiae morales conscientiae directivae tum ex Angelici Doctoris Discipulis, tum ex alijs theologis desumptae. Et in quatuor libros distinctae. Authore F. Ferdinando Ochm. vulgo Ianuszowski S. T. M. Ordinis Praedicatorum. Accesserunt in hac secunda editione, praeter breves additiones sc. de non alienandis Regularium bonis, de paupertate religiosa, de commutatione votorum, de non ambigendis inter religiosos officijs, de non aggravandis per Visitatores locis visitatis, examen Ordinandorum et Sententiae, tum ab Alexandro VII. tum ab Innocentio XI. damnatae. Superiorum permissu. Cracoviae, typis Nicolai Alexandri Schedel, 1694, 8․ E XVIII, 473.

10. Kazania na niedziele całego roku przez ks. Pawła Kaczyńskiego Societatis Jesu miane a za dozwoleniem starszych w Kolegium Kaliskim Soc. Jesu drukowane 1675, E XIX, 8.

11. Kazania na święta całego roku ks. Kaspra Balsama Soc. Jesu po śmierci jego za szczegulnym (!) J. K. Mci przywileiem i pozwoleniem zwierzchności wydane. Tomik II. W Poznaniu, w drukárni J. K. M. i Rzeczpltej, Societatis Jesu, 1764, $8^{\circ}$, E XII, 347.

12. Locupletissimus thesaurus continens varias et selectissimas benedictiones, conjurationes, exorcismos, absolutiones, ritus, administrationem sacramnetorum aliorumque munerum pastoralium ad utilitatem Christi fidelium et commodiorem usum parochorum omniumque sacerdotum tam saecularium quam religiosorum. Ex diversis ritualibus probatissimis authoribus collectus a Galasio di Cilia Can. Reg. Ordinis S. Augustini ad SS. Andream et Magnum Stattamhoffii cum gratia et privilegio Sac. Caes. Majestatis. Vohburgi, Sumptibus Quirini Heyll, 1709

13. Nauki, homilie i materyje kazań na wszystkie w całym roku dni święte ku większej Pana Boga chwale i czci Świętych Jego dla pożytku dusz ludzkich, pasterzów ich i kaznodziejów przysługi napisane, a na widok publiczny pod zaszczytem godnego imienia J. W. Imci Księdza Antoniego z Okęcia Okęckiego Biskupa Chełmskiego, z podziałem na końcu niektórych moralnych materyi w tych czterech tomach zawartych na kazania wszystkich w roku niedziel, wydane przez ks. Samuela Wysockiego Scholarum Piarum Ex-Assystenta Generalnego. Tom IV. W Warszawie, w Drukarni J. K. Mci i Rzeczypospolitej, w Kollegium księży Scholarum Piarum, 1770, 4․ o. E25.

14. Obowiązki osób stanu duchownego. Drugie Rekollekcyje dla kapłanów. O szczegulnych (!) występkach, których się powinni strzedz i cnotach, w których się powinni doskonalić kapłani i inni duchowni. Przez Księdza F.H. Sevoa direktora Seminarium Reneńskiego po francusku napisane. A przez Księdza P. Gniewczyńskiego K. S. K. Ł. na polski język przełożone. Tom czwarty, w Łowiczu w Drukarni JO. Księcia imć Prymasa Arcybiskupa Gnieźnieńskiego, 1795, 8․ E XXVII, 412.

${ }^{25}$ K. Estreicher w Bibliografii staropolskiej zapisał: „Czy wyszedł tom IV, który powinien był objąć kazania z ostatniego kwartału roku, nie wiem - ja się z nim nie spotkałem” (E XXXIII, 468). Ten tom posiada Biblioteka Jagiellońska. 
15. Ogród Różanny abo opisanie porządne dwu szczepów wonnej Róży Hierychuntskiej, to jest o dwu świętych Różańcach dwojga bractw błogosław[ionej] Panny Maryjej i Naświęt[szego] Imienia P[ana] Jezusowego w zakonie kaznodziejskim wszczepionych. Kwoli braciej i promotorom obojga Bractw świętych. Przez WO. Br. Waleryjana Lith[uanidesa] presidenta Bractw pomienionych tegoż zakonu, w Krakowie w Drukarni Franciszka Cezarego 1627, 4․ E I,152.

16. Processionale Responsoria, Antiphonas, aliaq. in Supplicationibus decantari solita, Complectens, ad normam S. Romanae Ecclesiae concinnatum. Usui Regni Poloniae Provincijs accommodatum, rubricarum notis ab Andrea Dabrowa Szczepanovio Artium Liberalium et Philosophiae in Universitate Crac: Baccalaureo Illustratum. Permissu Superiorum Reimpressum. Cum Gratia et Privilegio S. R. M. Cracoviae, Typis Collegij Majoris Universitatis Cracov., 1725, 4. E XXX, 215-216.

17. R. P. Vincentii Houdry e Societate Jesu bibliotheca concionatorum theologica, complectens mysteria Domini Nostri et B. Virginis. Insuper et ceremonias consuetudines et Ecclesiae placita, e Gallico sermone in latinum translata. Tomus secundus i quo continentur mysteria Domini Nostri a Resurrectione ad finem. Editio novissima. Venetiis, ex Typographia Balleoniana, $1759,8^{\circ}$. o. E.

18. R.P.F. Felicis Potestatis Panormitani Ordinis Minorum S. Francisci de Observantia Ministri Provincialis, Lectoris Jubilati et S. Officii Consultoris etc. Examen ecclesiasticum in quo universae materiae morales, omnesque fere casus conscientiae excogitabiles, solide ac perspicue resolvuntur cum denunciationibus ad monitoria atque edicta. Necnon instructione Sacrae Paenitentiariae, propositionibus damnatis, examine ordinandorum et arte praedicandi. Opus non tantum confessariis ac poenitentibus verum etiam praedicatoribus, ordinandis, missionariis, cunctisque ecclesiasticis summopere utile ac necessarium. In hac novissima editione accedunt suis quaeque locis infertae plures additiones numquam antea editae Romanorum Pontificum et praesertim Benedicti XIV. Constitutines ad theologiam moralem pertinentes, propositiones aliquae recenter ab iisdem Romanis Pontificibus damnatae atque in calce operis appendix thesium quesnellianarum. Venetiis, ex Typographia Remondiniana, 1759, $4^{\circ}$, o. E.

19. Religia i cnota chrześciańska po kaznodziejsku wykładane przez Wielebnego Ksiedza Sebastyana Ubermanowicza Societatis Jesu Teologa i Kaznodzieję Królewskiego do druku podane za dozwoleniem zwierzchności duchownej. W Kaliszu, w Drukarni J. K. M., 1769 [Księga trzecia części drugiej zamykająca kazania o cnotach Świętych Pańskich począwszy od maju aż do października. Rejestr drugiej i trzeciej księgi znajduje się na końcu]. E XXXII, 3.

20. Rituale Sacramentorum ac aliarum Ecclesiae ceremoniarum ex Decreto Synodi Provinc. Petric. ad uniformem Ecclesiarum Regni Poloniae usum, permissu superiorum reimpressum. Cum gratia et Privilegio S. R. M. Cracoviae Typis Collegij Majoris Universitatis Cracoviensis, 1725, 4․ E XXVI, 313.

21. Sancti Hieronymi presbyteri Epistolae selectae in tres libros ordine distributae et a D. Petro Canisio olim ad exemplar Mariani Victorii Reatini Episcopi Amerini emendatae Argumentis et uberrimo rerum et verborum indice locupletatae. In hac novissima editione Vita S. Doctoris nunc primum aulle notisque illustratae opera et studio 
Josephi Cathalani Congregationis S. Hieronymi Caritatis Presbyteri, sumptibus Remondini Venetii, in Typographia Bassanensi $1768,12^{\circ}$, o. E.

22. Tertulianus praedicans et supra quamlibet materiam omnibus anni dominicis et festis non ordinariis solum sed etiam extraordinariis singulisque Quadragesimae feriis paedicabilem ordine alphabetico copiose dispositum sex ad minus formans conciones, ingeniose adinventas, belle concinnatas et trinasub divisione illustras cum duplici indice, concionum scilicet et materiarum. Auctore R. P. Michaele Vivien Sacre Theologiae Lectore, Provinciae Recollectorum S. Francisci in Aquitania alumno necnon antiquo custodum custode. Editio octava, correcta et emendata. Tomus primus. Patavii ex Typographia Seminarii apud Joannem Manfre, 1747, $6^{\circ}$ - Tomus secundus, o. E.

23. Theologia moralis quadripartita incipientibus accomodata et in Aula Theologica S.J. Treviris publice exposita a R.P. Joanne Reuter ejusdem Societatis, SS. Theologiae Doctore in Universitate Trevirensi et professore publico nunc in usum et utilitatem plurium typis data cum praevia analysi doctrinae moralis a Sede Apostolica reprobatae. Pars III. Editio secunda auctior et emendatior, Coloniae Agrippinae, ex Officina Metternichiana, $1756,8^{\circ}$.

24. [Canon Missae Pontyficalis, Romae ex Typographia Vaticana], brak karty tytułowej, XVIII w.

25. [Kazania roczne na wszystkie niedziele ku największej czci i chwale Pana Boga], brak karty tytułowej, XVIII w.

\section{BIBLIOGRAFIA}

\section{Źródła}

Archiwum Archidiecezji Lubelskiej

Rep 60, sygn. A 150, A 151, A 152, A 154, A 159, A 161, A 164.

Archiwum parafialne w Kumowie, [b. sygn.], Visitatio generalis ecclesiae et beneficii parochialis kumoviensis per ... Adalbertum Leszczyc de Skarszewski ... Episcopum Hełmensem et Lublinensem coadiutorem Abbatem Suleioviensem ... 1798.

\section{Opracowania}

Estreicher Karol, Bibliografia staropolska, t. 12-35, Kraków 1891-2007.

Marczewski Jarosław R., Dzieje chetmskiej kapituły katedralnej obrządku łacińskiego, Lublin 2013.

Moskal Tomasz, Biblioteki parafialne $w$ archidiakonacie sandomierskim $w$ XVIII wieku, Sandomierz 2005. 


\title{
ANTIQUE BOOKS IN THE LIBRARY OF THE ROMAN CATHOLIC PARISH IN KUMÓW
}

\begin{abstract}
Summary
The Roman Catholic parish was established in Kumów in 1434. Like all parishes, it had its own library, which always contained liturgical books. A number of parish libraries also held books which were helpful in pastoral work, such as sermon collections. During the Trent reforms there were more and more books, primarily thanks to the Jesuits who dealt with theological writing and publishing activity. In the seventeenth and eighteeenth centuries, the number of books also increased in parish libraries, including the Kumów collection. We do not know much about the parish collection from the Old Polish period as its inventory has not survived. All the information we have is included in the reports of the bishop's visits; we do not, however, find sufficient detail to help us separate the books belonging to the Church from the private ones whose owners were individual parish priests. Only some of the books can be identified as those belonging to the parish, because they are mentioned several times in the reports of the visitors. The collection of antique books grew in the second half of the eighteenth century due to the bequests of two parish priests: Rev. Antoni Borowski and Rev. Antoni Wołoszyński. 25 antique books survived; they were kept in the basement of the presbytery for many years, deteriorating in unfavourable conditions.

This article presents a valuable contribution to research on the hitherto unknown parish libraries in the archdiocese of Lublin. Research into this area is worth undertaking, as the libraries are cultural sites frequently hiding rare books, which may otherwise be irretrievably lost.
\end{abstract}

Key words: Kumów; the parish of Kumów; library; antique books; the diocese of Lublin 